\title{
Studi Komparatif Kelayakan Usaha Pembuatan Dendeng Itik dengan Kerupuk Itik Di Kabupaten Hulu Sungai Utara (Studi Kasus: Usaha Pembuatan Dendeng Itik "Dhandy" dengan Kerupuk Itik "Mama Irfan" di Kecamatan Amuntai Tengah)
}

\section{(Comparative Study of The Feasibility of Making Fillet Spice Duck With Ducks Crackers on Hulu Sungai Utara (Case Study: Fillet Business Spice Ducks "Dhandy" with Duck Crackers "Mama Irfan" in District Central Amuntai))}

\author{
Dewi Susanti \\ Program Studi Agribisnis, Sekolah Tinggi Ilmu Pertanian Amuntai \\ dewisusanti884@yahoo.co.id
}

\begin{abstract}
ABSTRAK
Tujuan penelitian ini adalah (i) mengindentifikasi kelayakan nonfinansial usaha pembuatan dendeng itik dan kerupuk itik dilihat dari aspek pasar, aspek teknis, dan aspek manajemen (ii) menganalisis dan (iii) membandingkan kelayakan finansial usaha pembuatan dendeng itik dan kerupuk itik di Kecamatan Amuntai Tengah. Penelitian dilakukan pada usaha pembuatan dendeng itik "Dhandy" di Kelurahan Antasari dan kerupuk itik "Mama Irfan" di Desa Kota Raden Hulu Kecamatan Amuntai Tengah Kabupaten Hulu Sungai Utara pada bulan Mei - Agustus 2013. Metode penelitian yang digunakan adalah studi kasus dan pengumpulan data dengan wawancara. Analisis kualitatif tentang aspek pasar, teknis dan manajemen diolah secara deskriptif. Analisis kuantitatif menggunakan kriteria investasi yaitu analisis nilai bersih sekarang/NPV, tingkat pengembalian investasi/IRR, Net B/C Rasio dan masa pengembalian investasi, hasil kedua analisis dilanjutkan dengan analisis perbandingan. Hasil penelitian dari aspek non finansial menunjukkan usaha dendeng itik "Dhandy" dan kerupuk itik "Mama Irfan" dilihat dari aspek pasar atau teknis layak diusahakan. Namun dilihat dari aspek manajemen kedua usaha tersebut kurang layak karena masih dalam skala usaha kecil, diusahakan keluarga dan pelaksanaanya masih secara tradisional. Aspek finansial usaha dendeng itik "Dhandy" layak ditunjukkan nilai NPV sebesar Rp.5.950.594,-, IRR sebesar 12,92\%, net B/C sebesar 1,22 dan pay back period selama 4,5024 tahun. Sedangkan usaha kerupuk itik "Mama Irfan” juga layak ditunjukkan oleh nilai NPV sebesar Rp.31.874.247,-, IRR sebesar 51,93\%, net B/C sebesar 2,71 dan pay back period selama 2,4716 tahun. Analisis perbandingan menunjukkan usaha pembuatan kerupuk itik "Mama Irfan" lebih layak jika dibandingkan dengan usaha pembuatan dendeng itik "Dhandy”.
\end{abstract}

Kata Kunci: Dendeng, itik, kerupuk, kelayakan, usaha.

\section{ABSTRACT}

The purpose of this study is (i) identifying the non-financial feasibility of duck and duck cracker making business in terms of market, technical aspects and management aspects (ii) analyzing and (iii) comparing the financial feasibility of making duck and duck crackers in Central Amuntai District. The research was carried out on the "Dhandy" duck jerky in Antasari Village and "Mama Irfan" duck crackers in Kota Raden Hulu Village, Amuntai Tengah District, Hulu Sungai Utara Regency in May August 2013. The research method used was case studies and data collection with interviews. Qualitative analysis of market, technical and management aspects is processed descriptively. Quantitative analysis uses investment criteria, namely analysis of present net value / NPV, return on investment / IRR, Net B / C ratio and return period of investment, the results of the two analyzes are followed by comparative analysis. The results of the non-financial aspects showed that the "Dhandy" jerky duck and "Mama Irfan" duck crackers viewed from the market or technical aspects were worth the effort. However, viewed from the management aspect, the two businesses are not feasible because they are still in the scale of small businesses, family efforts and implementation are still traditional. The financial aspect of the "Dhandy" duck jerky business is worth showing the NPV value of Rp.5,950,594, - the IRR of 12.92\%, net B / C of 1.22 and the pay back period of 4,5024 years. Whereas the "Mama Irfan" duck cracker business is also worthy of the NPV value of Rp. 31,874,247, -, the IRR is 51.93\%, net B / C is 2.71 and the pay back period is 2.4716 years. Comparative analysis shows that the "Mama Irfan" duck cracker making business is more feasible compared to the "Dhandy" duck jerky making business. 
Keywords : Spice, duck, crackers, business, feasibility.

\section{PENDAHULUAN}

Dalam perekonomian Indonesia, sektor usaha kecil dan menengah memegang peranan penting dengan jumlah tenaga kerja yang mampu diserap oleh usaha kecil dan menengah tersebut. Selain memiliki arti strategis, usaha kecil menengah juga berfungsi sebagai sarana untuk memeratakan hasil-hasil pembangunan yang telah dicapai (Tambunan, 2003). Usaha Kecil Menengah (UKM) di Indonesia sangat besar peranannya. UKM merupakan salah satu sektor industri yang sedikit bahkan tidak sama sekali terkena dampak krisis global yang melanda dunia. Kalimantan Selatan khususnya Kabupaten Hulu Sungai Utara merupakan salah satu daerah yang memberdayakan UKM dalam pembangunan daerah.

Berdasarkan data yang diperoleh dari Dinas Perindustrian dan Perdagangan Kabupaten Hulu Sungai Utara pada tahun 2011 terdapat 11 jenis produk yang menjadi komoditi unggulan diantaranya adalah produk dendeng dan kerupuk dari itik.
Pemerintah daerah mendukung tumbuhnya industri-industri baru maupun lama untuk terus mengembangkannya (Dinas Perindustrian dan Perdagangan Kabupaten Hulu Sungai Utara, 2011). Produk dendeng itik dan kerupuk itik merupakan salah satu industri yang dikembangkan di Kecamatan Amuntai Tengah, di Kelurahan Antasari dan Desa Kota Raden Hulu. Jumlah permintaan dendeng itik maupun kerupuk itik ini semakin tahun semakin meningkat seiring dengan hari-hari besar keagamaan. Keuntungan perusahaan sangat dipengaruhi oleh jumlah produksi dan biaya produksi. Dendeng itik dan kerupuk itik ini terbuat dari daging itik afkir. Dengan adanya usaha ini diharapkan dapat menambah nilai tambah pada hasil produksi peternakan itik. Selain untuk meningkatkan harga jual usaha ini juga mampu untuk mengurangi jumlah pengangguran. Keadaan usaha dendeng itik dapat dilihat pada Tabel 1 sedangkan usaha kerupuk itik dapat dilihat pada Tabel 2.

Tabel 1. Data Pengusaha Dendeng Itik Di Kabupaten Hulu Sungai Utara Tahun 2013.

\begin{tabular}{clcc}
\hline No. & \multicolumn{1}{c}{ Nama Pengusaha } & Nama Merk & Jumlah Tenaga Kerja \\
\hline 1. & Risnin Hendaryati & Dhandy & 3 \\
2. & Ricky Tirta Maulana & Rina & 2 \\
3. & Hj. Iroh & - & 2 \\
4. & Ilin & - & 2 \\
5. & Sadariah & - & 2 \\
6. & Ida & - & 2 \\
7. & Hj. Ajat & - & 2 \\
8. & Hj. Ijah & - & 2 \\
9. & Hj. Silan & - & 2 \\
10. & Hj. Norasiah & - & 2 \\
11. & Hj. Ilin & - & 2 \\
12. & Hj. Erna & - & 2 \\
\hline \multicolumn{2}{r}{} & Jumlah &
\end{tabular}

Sumber: Data Survei Pendahuluan, 2013.

Tabel 1 menunjukkan bahwa usaha pembuatan dendeng itik cukup berkembang di Kabupaten Hulu Sungai Utara. Terdapat 12 unit usaha dengan jumlah tenaga kerja sebanyak 25 orang. Salah satu usaha dendeng itik yang memiliki kemasan dan izin usaha P.IRT terdapat di Kelurahan Antasari yaitu usaha pembuatan dendeng itik milik Ibu Risnin dengan nama merk "Dhandy". 
Dewi Susanti, Studi komparatif kelayakan usaha pembuatan...

Tabel 2. Data Pengusaha Kerupuk Itik Di Desa Kota Raden Hulu Tahun 2013.

\begin{tabular}{clcc}
\hline No. & \multicolumn{1}{c}{ Nama Pengusaha } & Nama Merk & Jumlah Tenaga Kerja \\
\hline 1. & Mariani & Mama Irfan & 2 \\
2. & Mahriana & Mama Rifki & 2 \\
3. & Hj. Aisyah & Mama Syahid & 2 \\
4. & Herlena Wati & Laila & 2 \\
5. & Raina & Ananda & 2 \\
6. & Rusmawardah & Mama Robi & 2 \\
7. & Nor Laila & Nusa Indah & 2 \\
8. & Rahmawati & Mama Ami 1 & 2 \\
9. & Hj. Saufiah & Mama Ami 2 & 2 \\
10. & Hj. Nafsiah & Mama Fajri & 2 \\
11. & Salma & Mama Indi & 2 \\
12. & Bawi & Bawi & 2 \\
13. & Helda & Helmina & 1 \\
\hline \multicolumn{2}{l}{} & & 25 \\
\hline
\end{tabular}

Sumber: Data Survei Pendahuluan, 2013.

Dari Tabel 2 diketahui jumlah pengusaha yang memproduksi kerupuk itik di Desa Kota Raden Hulu sebanyak 13 orang. Usaha tersebut dapat menampung banyak tenaga kerja dan memiliki nama merk yang berbeda-beda. Salah satu pengusaha kerupuk itik yaitu Ibu Mariani yang memproduksi kerupuk dengan merk "Mama Irfan" dengan jumlah tenaga kerja usaha tersebut sebanyak 2 orang. Menurut keterangan dari masyarakat setempat kerupuk itik "Mama Irfan" mempunyai banyak kelebihan dari yang lain di antaranya rasa dan kemasan yang menarik

Menurut Ibrahim (2003), Aspek studi kelayakan bisnis secara umum merupakan gambaran kegiatan usaha yang direncanakan sesuai dengan kondisi, potensi, serta peluang yang tersedia dari berbagai aspek. Aspekaspek dalam studi kelayakan antara lain aspek pasar, aspek teknis, aspek manajemen, dan aspek ekonomi/finansial.

Perhitungan kriteria investasi sangat erat hubungannya dengan kelayakan karena kriteria investasi digunakan untuk mengetahui sejauh mana gagasan usaha (proyek) yang direncanakan dapat memberikan manfaat (benefit) baik dilihat dari sosial maupn finansialnya. Hasil perhitungan kriteria merupakan indikator dari modal yang diinvestasikan yaitu perbandingan total benefit yang diterima dengan total biaya yang dikeluarkan dalam bentuk present value selama umur ekonomis.

Menurut Roefliana (2007), analisis kelayakan finansial produk madu dalam kemasan sachet menggunakan kriteria analisis NPV. Hasil perhitungan memberikan nilai positif yaitu sebesar Rp. 83.733.209,97. Nilai tersebut menunjukkan bahwa usaha madu sachet layak untuk dilaksanakan karena memberikan keuntungan selama umur proyek. Analisis sensitivitas melihat pengaruh peningkatan harga madu curah terhadap usaha madu sachet tetap mendapatkan keuntungan normal bila kenaikan harga madu curah tidak melebihi 7,3 persen pertahun.

Kelayakan usaha pembuatan dendeng itik dan kerupuk itik ini penting untuk dilakukan karena dengan kelayakan usaha bertujuan untuk menilai apakah usaha ini layak diusahakan agar usaha ini dapat terus dikembangkan. Hal ini dikarenakan dengan menggunakan bahan baku yang sama namun pengolahannya yang berbeda dan pada tingkat harga yang berbeda perlu dikaji kelayakannya diantara dua produksi tersebut. Untuk menilai kelayakan diperlukan penilaian terhadap aspek pasar, 
aspek teknis, dan aspek manajemen serta aspek finansialnya.

Tujuan penelitian ini adalah ; (i) mengindentifikasi kelayakan nonfinansial usaha pembuatan dendeng itik dan kerupuk itik dilihat dari aspek pasar, aspek teknis, dan aspek manajemen (ii) menganalisis kelayakan finansial usaha pembuatan dendeng itik dan kerupuk itik (iii) membandingkan kelayakan finansial usaha pembuatan dendeng itik dengan kerupuk itik.

\section{METODE PENELITIAN}

\section{Tempat dan Waktu Penelitian}

Penelitian ini dilakukan pada usaha pembuatan dendeng itik merk "Dhandy" di Kelurahan Antasari dan pada usaha pembuatan kerupuk itik merk "Mama Irfan" di Desa Kota Raden Hulu RT. 04 No. 008 Kecamatan Amuntai Tengah Kabupaten Hulu Sungai Utara. Pemilihan lokasi penelitian ini dilakukan secara sengaja (purposive) dengan pertimbangan bahwa usaha dendeng itik merk "Dhandy" dan kerupuk itik merk "Mama Irfan" merupakan usaha yang telah berkembang dengan kemasan menarik dan lokasi yang strategis serta memiliki biaya investasi bangunan yang dikeluarkan untuk proses produksi maupun pemasarannya. Waktu penelitian pada bulan Maret - Juli 2013 yang dmulai dengan persiapan penelitian, pengambilan data, dan dilanjutkan dengan penyusunan laporan penelitian.

\section{Jenis dan Sumber Data}

Jenis dan sumber data yang digunakan dalam penelitian ini adalah data primer dan data sekunder. Data primer diperoleh melalui wawancara langsung dengan pemilik usaha dendeng itik merk "Dhandy" dan usaha kerupuk itik merk "Mama Irfan" pada saat penelitian dengan menggunakan daftar pertanyaan. Data sekunder yang digunakan dalam penelitian ini berasal dari studi literatur berbagai buku, skripsi, internet, dan instansi-instansi terkait. Metode Pengumpulan Data

Metode penelitian yang digunakan adalah metode studi kasus metode pengumpulan data menggunakan metode wawancara.

\section{Analisis Data}

Analisis yang akan dilakukan selama penelitian ini adalah analisis kualitatif dan kuantitatif. Analisis kualitatif dilakukan untuk memperoleh gambaran tentang aspek pasar, aspek teknis, dan aspek manajemen dalam usaha ini diolah secara deskriptif. Analisis kuantitatif dilakukan untuk menganalisis kelayakan finansial dalam usaha pembuatan dendeng itik dan kerupuk itik menggunakan metode kriteria kelayakan investasi.

Aspek non finansial merupakan aspek-aspek yang terdiri dari aspek pasar, aspek teknis dan aspek manajemen (Rangkuti, 2012).

\section{Aspek Pasar}

Faktor yang perlu dinilai dalam aspek pasar antara lain:

a) Jumlah permintaan dendeng itik dan kerupuk itik di masa lalu dan masa kini serta kecendrungan dimasa yang akan datang.

b) Berdasarkan pada angka proyeksi (perkiraan) kemungkinan market potensial yang tersedia dimasa yang akan datang.

c) Berapa besar market share yang akan direncanakan berdasarkan pada rencana produksi.

d) Faktor apa saja yang mungkin mempengaruhi permintaan dendeng itik dan kerupuk itik di masa yang akan datang.

e) Strategi apa saja yang perlu dilakukan dalam meraih market share yang telah direncanakan.

\section{Aspek Teknis}

Aspek pokok yang dibahas dalam aspek teknis yaitu masalah lokasi, luas produksi, proses produksi, peralatan yang digunakan, serta lingkungan yang berhubungan dengan proses produksi.

\section{Aspek Manajemen}

Tugas pokok dari suatu manajemen ini adalah perencanaan, pengorganisasian, pengadaan tenaga kerja, pengarahan pekerjaan dan pelaksanaan pengawasan. 


\section{Aspek Kelayakan Finansial}

a. $\quad$ Net Present Value (NPV)

Net Present Value (NPV) merupakan selisih antara penerimaan dengan biaya yang telah di present value-kan.NPV adalah suatu proyek yang menunjukkan manfaat bersih yang diterima selama umur proyek pada tingkat bunga tertentu. Jika nilai NPV > dari 0 maka

$\mathrm{NPV}=\sum_{t}^{n}=\frac{B t-C t}{(1+i)^{t}}$

Keterangan:

$\mathrm{B}_{\mathrm{t}}=$ manfaat yang diperoleh tiap tahun

$\mathrm{C}_{\mathrm{t}}=$ biaya yang dikeluarkan tiap tahun

$\mathrm{n}=$ jumlah tahun

$\mathrm{i}=$ tingkat suku bunga (diskonto)

b. Internal Rate of Return (IRR)

Internal Rate of Return (IRR) adalah suatu tingkat bunga yang menyamakan present valuekas keluar yang diharapkan sama dengan kas masuk artinya menyebabkan nilai NPV $=0$.

$\mathrm{IRR}=i_{1}+\frac{N P V_{1}}{N P V_{1}-N P V_{2}}\left(i_{2}-i_{1}\right)$

Keterangan:

$i_{1} \quad=$ Tingkat suku bunga pada saat NPV bernilai positif

$i_{2}=$ Tingkat suku bunga pada saat

NPV bernilai negatif

$N P V_{1}=\mathrm{NPV}$ yang bernilai positif

$N P V_{2}=\mathrm{NPV}$ yang bernilai negatif

c. Net Benefit Cost Ratio (Net B/C Rasio)

Net Benefit Cost Ratio (Net B/C

Rasio) merupakan perbandingan antara net benefit yang telah di discount positif dengan yang negatif. Kriteria Net B/C Ratio adalah:

Net B/C Ratio > 0, maka NPV > 0 , Proyek menguntungkan

Net B/C Ratio < 0 , maka NPV $<0$, Proyek merugikan

Net $\mathrm{B} / \mathrm{C}$ Ratio $=0$, maka NPV $>=0$, Proyek tidak untung maupun tidak rugi.

NetB $/ \mathrm{C}=\frac{\sum_{\mathrm{i}=1}^{\mathrm{n}} \mathrm{N} \bar{B}_{\mathrm{i}}(+)}{\sum_{\mathrm{i}=1}^{\mathrm{n}} \mathrm{NB}_{\mathrm{i}}(-)}$

Keterangan:

$\mathrm{B}_{\mathrm{t}}=$ manfaat yang diperoleh tiap tahun

$\mathrm{C}_{\mathrm{t}}$ = biaya yang dikeluarkan tiap tahun

$\mathrm{n} \quad=$ jumlah tahun proyek tersebut layak diusahakan, sedangkan jika NPV < 0 maka usaha tersebut tidak layak untuk diusahakan. Hasil NPV yang sama dengan 0 menunjukkan bahwa usaha ini berada dalam keadaan break even point (BEP) diman $\mathrm{TR}=\mathrm{TC}$ artinya tidak untung dan tidak rugi.

$\mathrm{i} \quad=$ tingkat suku bunga (diskonto)

d. Pay Back Period (PBP)

Pay Back Period (PBP) adalah jangka waktu tertentu yang menunjukkan terjadinya arus penerimaan (cash in flows) secara komulatif sama dengan jumlah investasi dalam bentuk (present value). Analisis ini digunakan untuk mengetahui berapa lama usaha yang dikerjakan baru bisa mengembalikan investasi.

$$
+\frac{\sum_{i=1}^{n} \overline{\mathrm{i}}-\sum_{\mathrm{i}=1}^{\mathrm{n}} \overline{\mathrm{B}} \mathrm{icp}-1}{\mathrm{Bp}}
$$

$\mathrm{PBP}=\mathrm{Tp}-1+$

Keterangan :

PBP : Pay Back Period

PBP

Tp-1 : Tahun sebelum terdapat

Ii : Jumlah investasi yang telah di-discount

Bicp : Jumlah benefit di-discount sebelum PBP

Bp : Jumlah benefit pada PBP

\section{HASIL DAN PEMBAHASAN}

\section{Analisis Aspek Non Finansial \\ 1. Aspek Pasar}

Aspek pasar dalam studi kelayakan bisnis dan investasi membahas besarnya permintaan, penawaran, dan harga (Rangkuti, 2012). Usaha dendeng itik "Dhandy" dan kerupuk itik "Mama Irfan" juga memerlukan analisis aspek pasar agar produk yang dihasilkan dapat diterima oleh pasar. Pada penelitian ini aspek pasar yang dianalisis meliputi permintaan, penawaran, serta strategi pemasaran.

\section{Permintaan}


Untuk dendeng itik dalam 1 bulan habis terjual 100 ekor atau kotak dan untuk kerupuk itik yang diproduksi dan habis terjual adalah $30 \mathrm{~kg}$ dalam satu minggu sehingga dalam 1 bulan produksi untuk kerupuk itik adalah $120 \mathrm{~kg}$. Permintaan dendeng itik dan kerupuk itik ini meningkat saat Lebaran, liburan kenaikan kelas dan tahun baru.

Tabel 3. Jumlah Permintaan Dendeng Dan Kerupuk Itik Tahun 2013

\begin{tabular}{cccc}
\hline \multirow{2}{*}{ No. } & \multirow{2}{*}{ Lokasi Pemasaran } & \multicolumn{2}{c}{ Permintaan (Bulan) } \\
\cline { 3 - 4 } & Amuntai & Dendeng Itik (ekor) & Kerupuk Itik (kg) \\
\hline 1. & Tanjung & 60 & 50 \\
2. & Grogot & - & 20 \\
3. & Banjarmasin & 40 & 10 \\
4. & & & 40 \\
\hline
\end{tabular}

Sumber: Hasil Pengolahan Data Primer, 2013.

\section{Penawaran}

Menurut keterangan Ibu Risnin yaitu pemilik usaha dendeng itik, jumlah produksi dendeng itik selalu meningkat setiap tahunnya. Dari awal memulai usaha hanya memproduksi 5 ekor tiap bulan, sekarang sudah mencapai 100 ekor per bulannya. Tidak berbeda dengan usaha kerupuk itik, menurut keterangan Ibu Mariani yaitu pemilik usaha kerupuk itik "Mama Irfan",jumlah produksi kerupuk selalu meningkat setiap tahun. Jumlah produksi kerupuk itik $30 \mathrm{~kg} /$ minggu. Penawaran dendeng itik dan kerupuk itik ini akan lebih ditingkatkan pada saat Lebaran, liburan kenaikan kelas dan tahun ajaran baru. Jika pada hari biasa produksi dendeng itik 100 2. Harga ekor perbulan maka dengan adanya hari-hari tertentu bias mencapai 200 ekor perbulan. Sedangkan untuk kerupuk itik berkisar antara $240 \mathrm{~kg}$ perbulannya.

\section{Strategi Pemasaran}

Dalam strategi pemasaran terdapat bauran pemasaran (marketing mix) atau 4P yaitu produk (product), harga (price), distribusi (place) dan promosi (promotion).

1. Produk

Produk yang dihasilkan pada industri dendeng itik "Dhandy" adalah dendeng itik yang dipasarkan dalam bentuk kemasan 1 ekor perkotak. Untuk kerupuk "Mama Irfan" adalah kerupuk dipasarkan dalam bentuk kemasan 100 gram dan 200 gram.

Tabel 4. Daftar Harga Dendeng Itik dan Kerupuk Itik Tahun 2012.

\begin{tabular}{lcc}
\hline Jenis Ukuran & Dendeng Itik (Rp) & Kerupuk Itik \\
\hline Kecil & - & Rp.3.500.- \\
Besar & Rp. 65.000.- & Rp. 7.000.- \\
\hline
\end{tabular}

Sumber : Data Primer Usaha Kerupuk Merk Mama Irfan, 2013.

3. Distribusi

Pemasaran pada dendeng itik dan kerupuk itik terdapat dua saluran distribusi yang digunakan yaitu:

4. Promosi

Pemilik memperkenalkan produk kepada rekan-rekannya sehingga promosi dilakukan dengan mouth to
1. Pola I : Produsen

Konsumen

2. Pola II: Produsen

Pedagang Pengecer

Konsumen

mouth. Selain itu, produsen juga menggunakan pamflet untuk memperkenalkan produk serta mengikuti acara pameran yang dilakukan oleh 
Pemerintah Kabupaten Hulu Sungai Utara.

\section{Hasil Analisis Aspek Pasar}

Berdasarkan analisis aspek pasar dendeng itik "Dhandy" dan kerupuk itik "Mama Irfan" tersebut dapat disimpulkan bahwa usaha keduanya layak diusahakan.

\section{Aspek Teknis}

\section{Lokasi Usaha}

Lokasi usaha dendeng itik "Dhandy" terletak di Jalan Pangeran Antasari RT. 1 No .05 Kecamatan Amuntai Tengah Kabupaten Hulu Sungai Utara dan untuk kerupuk itik "Mama Irfan" di Desa Kota Raden Hulu RT. 04 No. 008 Kecamatan Amuntai Tengah Kabupaten Hulu Sungai Utara. Lokasi ini menguntungkan karena mudah dalam memasarkan produk dan mendapatkan bahan baku.

\section{Bahan Baku}

Untuk saat ini belum ada permasalahan untuk mendapatkan bahan baku sehingga proses produksi dapat dilaksanakan dengan lancar. Harga daging itik untuk dendeng itik adalah Rp45.000,/ekor sedangkan harga itik untuk kerupuk itik adalah $\mathrm{Rp} 35.000$,-/ekor.

\section{Kapasitas Produksi}

Saat ini kapasitas produksi usaha dendeng itik untuk hari normal adalah 100 ekor perbulan sedangkan kerupuk itik 120 kg/bulan.

\section{Proses Produksi}

Proses pembuatan dendeng itik meliputi pencucian, pemisahan daging dengan tulang, pencampuran dengan bumbu, diamkan sampai 1 malam, perjemuran dan pengemasan.

Sedangkan proses pembuatan kerupuk itik adalah pengadonan, pencetakan, perebusan atau pengukusan, pengirisan dan pengeringan.

\section{Lay Out Usaha}

Lay out merupakan suatu proses dalam penetuan bentuk dan penempatan fasilitas yang dapat menentukan efisiensi produksi/operasi. Lokasi produksi terletak menyatu dengan kediaman produsen dalam satu bangunan. Struktur ruangan untuk proses produksi ditata sesuai dengan alur produksi. Ruangan produksi terbagi empat, yaitu ruang pencucian, ruang produksi, ruang penjemuran, dan ruang pengemasan.

\section{Hasil Analisis Aspek Teknis}

Berdasarkan hasil analisis aspek teknis, usaha dendeng itik "Dhandy" dan kerupuk itik "Mama Irfan" layak diusahakan.

\section{Aspek Manajemen}

Usaha pembuatan dendeng itik "Dhandy" dan usaha kerupuk itik "Mama Irfan" merupakan bentuk usaha perseorangan. Produsen melaksanakan usaha secara tradisional. Pemilik usaha merangkap sebagai pemimpin usaha yang memegang kendali atas semua keputusan dalam usahanya.

Meskipun pelaksanaan usaha ini masih tradisional, usaha dendeng itik dan kerupuk itik sudah memiliki pembagian tugas yang jelas terhadap para tenaga kerjanya. Dari segi administrasi usaha pembuatan dendeng itik dan kerupuk itik belum memiliki pembukuan usaha.

\section{Hasil Analisis Aspek Manajemen}

Usaha pembuatan dendeng itik "Dhandy" dan kerupuk itik "Mama Irfan"masih kurang layak apabila dilihat dari aspek manajemen.

\section{Analisis Aspek Finansial}

\section{Analisis Aspek Finansial Usaha Pembuatan Dendeng Itik \\ 1) Analisis Inflow Usaha Pembuatan Dendeng Itik}




\begin{tabular}{cccc}
\hline Tahun & $\begin{array}{c}\text { Produksi } \\
\text { (ekor) }\end{array}$ & Harga per kotak (Rp) & Pendapatan (Rp) \\
\hline 1 & 720 & 50.000 & 36.000 .000 \\
2 & 1.040 & 55.000 & 57.200 .000 \\
3 & 1.300 & 60.000 & 78.000 .000 \\
4 & 1.300 & 65.000 & 84.500 .000 \\
\hline
\end{tabular}

Sumber: Hasil Pengolahan Data Primer, 2013.

\section{2) Analisis Outflow Usaha Dendeng Itik}

Jumlah seluruh barang yang dinvestasikan pada awal usaha pembuatan dendeng itik "Dhandy" Kecamatan Amuntai
Tengah adalah 15 unit dengan nilai investasi awal sebesar Rp.27.050.000,- dan jumlah biaya penyusutan adalah Rp. 2.905.000,Itahun.

Tabel 6. Biaya Tetap Pada Usaha Pembuatan Dendeng Itik "Dhandy" Kelurahan Antasari Kecamatan Amuntai Tengah

\begin{tabular}{lcc}
\hline Jenis Biaya Tetap & Biaya Tetap/Bulan (Rp) & Biaya Tetap/Tahun(Rp) \\
\hline Listrik & 25.000 & 300.000 \\
Air & 25.000 & 300.000 \\
Biaya Penyusutan Investasi & 242.083 & 2.905 .000 \\
\hline Jumlah & 292.083 & 3.505 .000 \\
\hline
\end{tabular}

Sumber: Hasil Pengolahan Data Primer, 2013

Tabel 6 menunjukkan bahwa jumlah biaya tetap per bulan sebesar Rp.292.083,dan biaya tetap per tahun sebesar Rp.3.505.000,-.
Biaya variabel adalah biaya yang besarnya dipengaruhi oleh jumlah produk yang dihasilkan dalam proses produksi.

Tabel 7. Total Biaya Variabel Pada Usaha Pembuatan Dendeng Itik "Dhandy" Kecamatan Amuntai Tengah

\begin{tabular}{ccccc}
\hline \multirow{2}{*}{ Uraian } & \multicolumn{4}{c}{ Total Biaya Variabel Per Tahun (Rp) } \\
\cline { 2 - 5 } & 1 & 2 & 3 & 4 \\
\hline Pembuatan dendeng itik & 27.720 .000 & 45.110 .000 & 64.967 .500 & 65.520 .000 \\
\hline Jumlah & 27.720 .000 & 45.110 .000 & 64.967 .500 & 65.520 .000 \\
\hline
\end{tabular}

Total biaya variabel usaha dendeng itik pada tahun ke-1 sebesar Rp.27.720.000,-. Pada tahun ke-2 biaya variabel bertambah menjadi Rp.45.110.000,-, hal ini terjadi karena adanya penambahan volume produksi. Tahun ke-3 sebesar Rp.
64.967.500,- dan tahun ke-4 total biaya variabel sebesar Rp.65.520.000,-.

Biaya operasional pada usaha dendeng itik adalah seluruh biaya yang dikeluarkan dalam proses produksi.

Tabel 8. Total Biaya Operasional Pada Usaha Pembuatan Dendeng Itik di Kelurahan Antasari Kecamatan Amuntai Tengah 


\begin{tabular}{cccccc}
\hline \multirow{2}{*}{ No. } & \multirow{2}{*}{ Keterangan } & \multicolumn{4}{c}{ Tahun } \\
\cline { 3 - 6 } & & 1 & 2 & 3 & 4 \\
\hline 1 & Biaya variabel & 27.720 .000 & 45.110 .000 & 64.947 .500 & 65.520 .000 \\
\hline 2 & Biaya tetap & 3.505 .000 & 3.505 .000 & 3.505 .000 & 3.505 .000 \\
\hline \multirow{2}{*}{ Jumlah $(\mathrm{Rp})$} & 31.225 .000 & 48.615 .000 & 68.552 .500 & 69.025 .000 \\
\hline \multicolumn{4}{c}{ Rata-rata $(\mathrm{Rp})$} & & 54.354 .375 \\
\hline
\end{tabular}

Sumber: Hasil Pengolahan Data Primer, 2013

Tabel 8 menunjukkan bahwa rata-rata biaya operasional usaha pembuatan dendeng itik

\section{3) Analisis Finansial Usaha Pembuatan Dendeng Itik}

"Dhandy" Kecamatan Amuntai Tengah selama 4 tahun sebesar Rp.54.354.375,-.

Tabel 9. Persiapan Perhitungan Analisis Kelayakan Investasi NPV Pada Usaha Pembuatan Dendeng Itik "Dhandy" di Kecamatan Amuntai Tengah

\begin{tabular}{clccccc}
\hline \multirow{2}{*}{ No. } & \multicolumn{1}{c}{ Uraian } & \multicolumn{5}{c}{ Tahun } \\
\cline { 2 - 7 } & & 0 & 1 & 2 & 3 & 4 \\
\hline 1 & Penerimaan & - & 36.000 .000 & 57.200 .000 & 78.000 .000 & 84.500 .000 \\
& Biaya investasi & 27.050 .000 & - & - & - & - \\
2 & Biaya operasional & - & 31.225 .000 & 48.615 .000 & 68.552 .500 & 69.025 .000 \\
& Total cost & 27.050 .000 & 31.225 .000 & 48.615 .000 & 68.552 .500 & 69.025 .000 \\
3 & Net benefit & -27.050 .000 & 4.775 .000 & 8.585 .000 & 9.447 .500 & 15.475 .000 \\
4 & DF 5,25\% & 1,0000 & 0,9501 & 0,9027 & 0,8577 & 0,8149 \\
5 & Present value & -27.050 .000 & 4.536 .817 & 7.749 .900 & 8.103 .089 & 12.610 .788 \\
6 & NPV= total value & & & 5.950 .594 & & \\
\hline
\end{tabular}

Sumber: Hasil Pengolahan Data Primer, 2013.

Berdasarkan Tabel 9 dapat dilihat nilai Net Present Value (NPV) sebesar Rp.5.950.594,-. Hasil menunjukkan bahwa NPV > 0, ini berarti usaha Pembuatan

\section{Net Present Value (NPV) Usaha Pembuatan Dendeng Itik}

\section{Internal Rate Of Return (IRR) Usaha Pembuatan Dendeng Itik}

Tabel 10. Persiapan Perhitungan Analisis Kelayakan Investasi IRR Pada Usaha Pembuatan Dendeng Itik "Dhandy"di Kecamatan Amuntai Tengah

\begin{tabular}{llccccc}
\hline \multirow{2}{*}{ No. } & \multirow{2}{*}{ Uraian } & \multicolumn{5}{c}{ Tahun } \\
\cline { 3 - 7 } & & 0 & 1 & 2 & 3 & 4 \\
\hline 1 & Net benefit & -27.000 .000 & 4.775 .000 & 8.585 .000 & 9.447 .500 & 15.475 .000 \\
2 & DF 5,25\% & 1,0000 & 0,9501 & 0,9027 & 0,8577 & 0,8149 \\
3 & Present value & -27.000 .000 & 4.536 .817 & 7.749 .900 & 8.103 .089 & 12.610 .788 \\
4 & DF 13\% & 1,0000 & 0,8850 & 0,7831 & 0,6931 & 0,6133 \\
5 & Present value & -27.000 .000 & 4.225 .664 & 6.723 .314 & 6.547 .591 & 59.491 .107 \\
6 & NPV 1 & & & 5.950 .594 & & \\
7 & NPV 2 & & & -62.323 & & \\
\hline
\end{tabular}

Sumber: Hasil Pengolahan Data Primer, 2013

Nilai IRR berada antara nilai NPV positif dan NPV negatif yaitu NPV sama dengan nol $(\mathrm{NPV}=0)$, maka hasil dendeng itik "Dhandy" di Kelurahan Antasari Kecamatan Amuntai Tengah layak diusahakan/dilanjutkan. 
IRR > SOCC, dengan demikian usaha pembuatan dendeng itik "Dhandy" di
Kelurahan Antasari Kecamatan Amuntai Tengah layak diusahakan.

\section{Net Benefit Cost Ratio (Net B/C) Usaha Pembuatan Dendeng Itik}

Tabel 11. Persiapan Perhitungan Analisis Kelayakan Investasi Net B/C Rasio Pada Usaha Pembuatan Dendeng Itik "Dhandy"di Kecamatan Amuntai Tengah

\begin{tabular}{clccccc}
\hline No. & Uraian & \multicolumn{5}{c}{ Tahun } \\
\cline { 3 - 7 } & & 0 & 1 & 2 & 3 & 4 \\
\hline 1 & Penerimaan & - & 36.000 .000 & 57.200 .000 & 78.000 .000 & 84.500 .000 \\
2 & Biaya investasi & 27.050 .000 & - & - & - & - \\
& Biaya operasional & - & 31.225 .000 & 48.615 .000 & 68.552 .500 & 69.025 .000 \\
& Total cost & 27.050 .000 & 31.225 .000 & 48.615 .000 & 68.552 .500 & 69.025 .000 \\
3 & Net Benefit & -27050000 & 4775000 & 8585000 & 9447500 & 15475000 \\
4 & DF 5,25\% & 1 & 0.9501 & 0.9027 & 0.8577 & 0.8149 \\
5 & Present Value & -27050000 & 4536817 & 7749900 & 8103089 & 12610788 \\
\hline
\end{tabular}

Sumber: Hasil Pengolahan Data Primer, 2013

Berdasarkan Tabel 11 dapat dihitung nilai Net $B / C$ yaitu 1,22 . Hal ini berarti setiap Rp.1,00 yang dikeluarkan akan menghasilkan manfaat bersih sebesar

\section{Payback Period (PBP) Usaha Pembuatan}

\section{Dendeng Itik}

Tabel 12. Persiapan Perhitungan Analisis Kelayakan Investasi Payback Period (PBP) Pada Usaha Pembuatan Dendeng Itik "Dhandy"di Kecamatan Amuntai Tengah

\begin{tabular}{llccccc}
\hline \multirow{2}{*}{ No. } & \multicolumn{1}{c}{ Uraian } & \multicolumn{5}{c}{ Tahun } \\
\cline { 2 - 7 } & & 0 & 1 & 2 & 3 & 4 \\
\hline 1 & Penerimaan & - & 36.000 .000 & 57.200 .000 & 78.000 .000 & 84.500 .000 \\
2 & Biaya investasi & 27.050 .000 & - & - & - & - \\
& Biaya operasional & - & 31.225 .000 & 48.615 .000 & 68.552 .500 & 69.025 .000 \\
& Total cost & 27.050 .000 & 31.225 .000 & 48.615 .000 & 68.552 .500 & 69.025 .000 \\
3 & Net benefit & -27.050 .000 & 4.775 .000 & 8.585 .000 & 9.447 .500 & 15.475 .000 \\
4 & DF 5,25\% & 1,0000 & 0,9501 & 0,9027 & 0,8577 & 0.8149 \\
5 & Present value & -27.050 .000 & 4.536 .817 & 7.749 .900 & 8.103 .089 & 12.610 .788 \\
\hline
\end{tabular}

Sumber: Hasil Pengolahan Data Primer, 2013.

Berdasarkan Tabel 12 dapat dihitung payback period pada usaha pembuatan

\section{Analisis Aspek Finansial Usaha Pembuatan Kerupuk Itik}

Rp.1,22. Nilai Net B/C yang diperoleh lebih besar dari 1, sehingga usaha pembuatan dendeng itik layak dilaksanakan.

Tabel 13. Perkiraan Pendapatan Penjualan Usaha Kerupuk Itik "Mama Irfan" Per Tahun di Desa Kota Raden Hulu Kecamatan Amuntai Tengah 
Dewi Susanti, Studi komparatif kelayakan usaha pembuatan...

\begin{tabular}{cccc}
\hline 1 & 720 & 30.000 & 21.600 .000 \\
2 & 1.170 & 30.000 & 35.100 .000 \\
3 & 1.560 & 32.500 & 50.700 .000 \\
4 & 1.560 & 35.000 & 54.600 .000 \\
\hline
\end{tabular}

Sumber: Hasil Pengolahan Data Primer, 2013.

\section{2) Analisis Outflow Usaha Pembuatan Kerupuk Itik}

Jumlah seluruh barang yang diinvestasikan pada awal usaha pembuatan kerupuk itik di Desa Kota Raden Hulu
Kecamatan Amuntai Tengah adalah 22 unit dengan nilai investasi awal sebesar Rp 18.665.000,- dan jumlah biaya penyusutan adalah Rp.2.226.200,-/tahun.

Tabel 14. Biaya Tetap Pada Usaha Pembuatan Kerupuk Itik Di Desa Kota Raden Hulu Kecamatan Amuntai Tengah

\begin{tabular}{lcc}
\hline \multicolumn{1}{c}{ Jenis Biaya Tetap } & Biaya Tetap/Bulan $(\mathrm{Rp})$ & Biaya Tetap/Tahun $(\mathrm{Rp})$ \\
\hline Listrik & 100.000 & 1.200 .000 \\
Air & 50.000 & 600.000 \\
Telepon & 25.000 & 300.000 \\
Biaya Penyusutan Investasi & 185.500 & 2.226 .200 \\
\hline Jumlah & 360.500 & 4.326 .200
\end{tabular}

Sumber: Hasil Pengolahan Data Primer, 2013

Tabel 14 menunjukkan bahwa Rp.360.500,- dan biaya tetap per tahun jumlah biaya tetap per bulan sebesar sebesar Rp.4.326.200,-.

Tabel 15. Total Biaya Variabel Pada Usaha Pembuatan Kerupuk Itik "Mama Irfan”di Desa Kota Raden Hulu Kecamatan Amuntai Tengah

\begin{tabular}{lcccc}
\hline \multirow{2}{*}{ Uraian } & \multicolumn{4}{c}{ Total Biaya Variabel Per Tahun (Rp) } \\
\cline { 2 - 5 } & 1 & 2 & 3 & 4 \\
\hline Pembuatan kerupuk itik & 11.382 .000 & 18.495 .750 & 27.675 .500 & 28.437 .500 \\
\hline Jumlah & 11.382 .000 & 18.495 .750 & 27.675 .500 & 28.437 .500 \\
\hline
\end{tabular}

Sumber: Hasil Pengolahan Data Primer, 2013.

Total biaya variabel pembuatan kerupuk itik pada tahun ke-1 sebesar Rp.11.382.000,-. Pada tahun ke-2, ke-3 dan

ke-4 biaya variabel bertambah hal ini terjadi karena adanya penambahan volume produksi.

Tabel 16.Total Biaya Operasional Pada Usaha Pembuatan Kerupuk Itik “Mama Irfan” di Desa Kota Raden Hulu Kecamatan Amuntai Tengah

\begin{tabular}{cccccc}
\hline \multirow{2}{*}{ No. } & \multirow{2}{*}{ Keterangan } & \multicolumn{4}{c}{ Tahun } \\
\cline { 3 - 6 } & & 1 & 2 & 3 & 4 \\
\hline 1 & Biaya variabel & 11.382 .000 & 18.495 .750 & 27.675 .500 & 28.437 .500 \\
2 & Biaya tetap & 4.326 .200 & 4.326 .200 & 4.326 .200 & 4.326 .200 \\
\hline & Jumlah $(\mathrm{Rp})$ & 15.708 .200 & 22.821 .950 & 31.983 .700 & 32.763 .700 \\
\hline & \multicolumn{4}{c}{25.819 .387} \\
\hline
\end{tabular}

Sumber: Hasil Pengolahan Data Primer, 2013 


\section{3) Analisis Finansial Usaha Pembuatan Kerupuk Itik \\ Net Present Value (NPV) Usaha Pembuatan Kerupuk Itik}

Tabel 17. Persiapan Perhitungan Analisis Kelayakan Investasi NPV Pada Usaha Pembuatan Kerupuk Itik di Desa Kota Raden Hulu Kecamatan Amuntai Tengah

\begin{tabular}{clccccc}
\hline \multirow{2}{*}{ No. } & \multicolumn{1}{c}{ Uraian } & \multicolumn{5}{c}{ Tahun } \\
\cline { 3 - 7 } & & 0 & 1 & 2 & 3 & 4 \\
\hline 1 & Penerimaan & - & 21.600 .000 & 35.100 .000 & 50.700 .000 & 54.600 .000 \\
2 & Biaya investasi & 18.655 .000 & - & - & - & - \\
3 & Biaya operasional & - & 15.708 .200 & 22.821 .950 & 31.983 .700 & 32.763 .700 \\
4 & Total cost & 18.655 .000 & 15.708 .200 & 22.821 .950 & 31.983 .700 & 32.763 .700 \\
5 & Net benefit & -18.655 .000 & 5.891 .800 & 12.278 .050 & 18.716 .300 & 21.836 .300 \\
6 & DF 5,25\% & 1,0000 & 0,9501 & 0,9027 & 0,8577 & 0.8149 \\
& Present value & -18.655 .000 & 5.597 .911 & 11.083 .715 & 16.052 .914 & 17.794 .707 \\
& NPV= total value & & & 31.874 .247 & & \\
\hline
\end{tabular}

Sumber: Hasil Pengolahan Data Primer, 2013.

Berdasarkan Tabel 17 dapat dilihat nilai Net Present Value (NPV) sebesar Rp.31.874.247,-. Hasil menunjukkan bahwa NPV > 0, ini berarti usaha pembuatan kerupuk itik di Desa Kota Raden Hulu Kecamatan Amuntai Tengah layak diusahakan/dilanjutkan.

\section{Internal Rate Of Return (IRR) Usaha Pembuatan Kerupuk Itik}

Tabel 18. Persiapan Perhitungan Analisis Kelayakan Investasi IRR Pada Usaha Pembuatan Kerupuk Itik di Desa Kota Raden Hulu Kecamatan Amuntai Tengah

\begin{tabular}{ccccccc}
\hline \multirow{2}{*}{ No. } & \multirow{2}{*}{ Uraian } & \multicolumn{5}{c}{ Tahun } \\
\cline { 3 - 7 } & & 0 & 1 & 2 & 3 & 4 \\
\hline 1 & Net benefit & -18.655 .000 & 5.891 .800 & 12.278 .050 & 18.716 .300 & 21.836 .300 \\
2 & DF 5,25\% & 1,0000 & 0,9501 & 0,9027 & 0,8577 & 0,8149 \\
3 & Present value & -18.655 .000 & 5.597 .911 & 11.083 .715 & 16.052 .914 & 17.794 .707 \\
4 & DF 52\% & 1,0000 & 0,6579 & 0,4328 & 0,2848 & 0,1873 \\
5 & Present value & -18.655 .000 & 3.876 .184 & 5.314 .253 & 5.329 .534 & 4.090 .767 \\
6 & NPV 1 & & & 31.874 .247 & & \\
7 & NPV 2 & & & -44.262 & & \\
\hline
\end{tabular}

Sumber: Hasil Pengolahan Data Primer, 2013.

Berdasarkan Tabel 1, diperoleh nilai IRR berada antara nilai NPV positif dan NPV negatif yaitu NPV sama dengan nol $(\mathrm{NPV}=0)$, maka hasil perhitungan tersebut menunjukkan IRR sebesar $51,93 \%$ dan
Social Opportunity Cost of Capital (SOCC) sebesar 5,25\%, ini berarti IRR > SOCC, dengan demikian usaha pembuatan kerupuk itik di Desa Kota Raden Hulu Kecamatan Amuntai Tengah layak diusahakan.

\section{Net Benefit Cost Ratio (Net B/C) Usaha Pembuatan Kerupuk Itik}

Tabel 19. Persiapan Perhitungan Analisis Kelayakan Investasi Net B/C Rasio Pada Usaha Pembuatan Kerupuk Itik di Desa Kota Raden Hulu Kecamatan Amuntai Tengah

\begin{tabular}{llllclc}
\hline \multirow{2}{*}{ No } & \multirow{5}{*}{ Uraian } & 0 & 1 & 2 & 3 & 4 \\
\cline { 3 - 6 } & & &
\end{tabular}


Dewi Susanti, Studi komparatif kelayakan usaha pembuatan..

\begin{tabular}{|c|c|c|c|c|c|c|}
\hline 1 & Penerimaan & - & 21.600 .000 & 35.100 .000 & 50.700 .000 & 54.600 .000 \\
\hline 2 & Biaya investasi & 18.655 .000 & 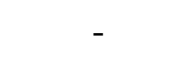 & - & - & - \\
\hline & $\begin{array}{l}\text { Biaya } \\
\text { operasional }\end{array}$ & - & 15.708 .200 & 22.821 .950 & 31.983 .700 & 32.763 .700 \\
\hline & Total cost & 18.655 .000 & 15.708 .200 & 22.821 .950 & 31.983 .700 & 32.763 .700 \\
\hline 3 & Net Benefit & -18655000 & 5891800 & 12278050 & 18716300 & 21836300 \\
\hline 4 & DF $5,25 \%$ & 1 & 0.9501 & 0.9027 & 0.8577 & 0.8149 \\
\hline 5 & Present Value & -18655000 & 5597911 & 11083715 & 16052914 & 17794707 \\
\hline
\end{tabular}

Sumber: Hasil Pengolahan Data Primer, 2013.

Berdasarkan Tabel 19 dapat dihitung nilai Net B/C yaitu 2,71. Hal ini berarti setiap Rp.1,00 yang dikeluarkan akan menghasilkan manfaat bersih sebesar
Rp.2,71. Nilai Net B/C yang diperoleh lebih besar dari 1, sehingga usaha pembuatan kerupuk itik layak dilaksanakan.

\section{Payback Period (PBP) Usaha Pembuatan Kerupuk Itik}

Tabel 20. Persiapan Perhitungan Analisis Kelayakan Investasi Payback Period (PBP) Pada Usaha Pembuatan Kerupuk Itik di Desa Kota Raden Hulu Kecamatan Amuntai Tengah

\begin{tabular}{ccccccc}
\hline \multirow{2}{*}{ No. } & \multicolumn{1}{c}{ Uraian } & \multicolumn{5}{c}{ Tahun } \\
\cline { 3 - 7 } & & 0 & 1 & 2 & 3 & 4 \\
\hline 1 & Penerimaan & - & 21.600 .000 & 35.100 .000 & 50.700 .000 & 54.600 .000 \\
& Biaya investasi & 18.655 .000 & - & - & - & - \\
2 & Biaya operasional & - & 15.708 .200 & 22.821 .950 & 31.983 .700 & 32.763 .700 \\
& Total cost & 18.655 .000 & 15.708 .200 & 22.821 .950 & 31.983 .700 & 32.763 .700 \\
3 & Net benefit & -18.655 .000 & 5.891 .800 & 12.278 .050 & 18.716 .300 & 21.836 .300 \\
4 & DF 5,25\% & 1,0000 & 0,9501 & 0,9027 & 0,8577 & 0,8149 \\
5 & Present value & -18.655 .000 & 5.597 .911 & 11.083 .715 & 16.052 .914 & 17.794 .707 \\
\hline
\end{tabular}

Sumber: Hasil Pengolahan Data Primer, 2013.

Berdasarkan Tabel 19 dapat dihitung payback period pada usaha pembuatan kerupuk itik di Desa Kota Raden Hulu
Kecamatan Amuntai Tengah yaitu 2,4716 tahun atau 2 tahun 5 bulan 19 hari.

\section{Analisis Perbandingan Usaha Pembuatan Dendeng Itik Dengan Kerupuk Itik}

Tabel 21. Analisis Perbandingan Usaha Dendeng Itik Dengan Kerupuk Itik

\begin{tabular}{ccc}
\hline Kriteria & Dendeng Itik & Kerupuk Itik \\
\hline NPV & Rp. $5.950 .594,-$ & Rp.31.874.247,- \\
IRR & $12,92 \%$ & $51,93 \%$ \\
NET B/C & 1,22 & 2,71 \\
PAYBACK PERIOD & 4,5024 tahun & 2,4716 tahun
\end{tabular}

Sumber: Hasil Pengolahan Data Primer, 2013.

Berdasarkan analisis perbandingan diartikan usaha pembuatan kerupuk itik kelayakan usaha dendeng itik dengan lebih layak diusahakan. kerupuk itik pada table 20 menunjukkan bahwa dari kedua usaha tersebut dapat 
Usaha dendeng itik "Dhandy" dan usaha pembuatan kerupuk itik "Mama Irfan" jika dilihat dari aspek pasar atau teknis layak diusahakan. Namun dilihat dari aspek manajemen usaha dendeng itik "Dhandy" dan kerupuk itik "Mama Irfan" kurang layak karena usaha tersebut masih dalam skala usaha yang kecil serta merupakan usaha keluarga dan pelaksanaanya masih secara tradisional. Tetapi dari segi administarsi usaha kerupuk itik "Mama Irfan" lebih layak dibandingkan dendeng itik "Dhandy".

Secara analisis finansial menunjukkan bahwa usaha dendeng itik "Dhandy" layak diusahakan. Hal ini ditunjukkan oleh nilai NPV sebesar Rp.5.950.594,-, IRR sebesar $12,92 \%$, net $\mathrm{B} / \mathrm{C}$ sebesar 1,22 dan pay back period selama 4,5024 tahun. Sedangkan untuk usaha pembuatan kerupuk itik "Mama Irfan" juga layak diusahakan. Hal ini ditunjukkan oleh nilai NPV sebesar Rp.31.874.247,-, IRR sebesar 51,93\%, net B/C sebesar 2,71 dan pay back period selama 2,4716 tahun. Analisis perbandingan menunjukkan usaha pembuatan kerupuk itik "Mama Irfan" lebih layak jika dibandingkan dengan usaha pembuatan dendeng itik "Dhandy".

\section{DAFTAR PUSTAKA}

Dinas Perindustrian dan Perdagangan Kabupaten Hulu Sungai Utara 2012. Data Industri Kecil Menengah dan Industri Rumah Tangga Kabupaten Hulu Sungai Utara. Amuntai.

Ibrahim, Y. 2003. Studi Kelayakan Bisnis Edisi Revisi. PT Rineka Cipta, Jakarta.

Rangkuti, F. 2012. Studi Kelayakan Bisnis dan Investasi.PT.Garamedia. Jakarta.

Roefliana, I. 2007. Analisis Kelayakan fFnansial Produk Madu Dalam Kemasan Sachet.Skripsi.IPB. Bogor. http://repository.ipb.ac.id/bitstream/h andle/123456789/49345/E07iro.pdf?s equence $=1$. Diakses tanggal 26 April 2013

Tambunan, T. 2003. Perekonomian Indonesia.Ghalia Indonesia. Jakarta. 